\title{
Publisher Correction: The Value of Cardiopulmonary Exercise Testing in Determining Severity in Patients with both Systolic Heart Failure and COPD
}

\author{
Cássia da Luz Goulart, Polliana Batista dos Santos, Flávia Rossi Caruso, \\ Guilherme Peixoto Tinoco Arêas, Renan Shida Marinho, Patricia de Faria Camargo, \\ Tiago da Silva Alexandre, Claudio R. Oliveira, Andréa Lúcia Gonçalves da Silva, \\ Renata Gonçalves Mendes, Meliza Goi Roscani \& Audrey Borghi-Silva
}

Correction to: Scientific Reports https://doi.org/10.1038/s41598-020-61199-5, published online 09 March 2020

The original version of this Article contained an error in the order of author names, which were incorrectly given as 'Cássia da Luz Goulart, Polliana Batista dos Santos, Flávia Rossi Caruso, Guilherme Peixoto Tinoco Arêas, Renan Shida Marinho, Patricia de Faria Camargo, Tiago da Silva Alexandre, Claudio R. Oliveira, Andréa Lúcia Gonçalves da Silva, Audrey Borghi-Silva, Renata Gonçalves Mendes \& Meliza Goi Roscani'.

Additionally, Meliza Goi Roscani was incorrectly affiliated with 'Cardiopulmonary Physiotherapy Laboratory, Physiotherapy Department, Federal University of Sao Carlos, UFSCar, Rod Washington Luis, KM 235, Monjolinho, CEP: 13565-905, Sao Carlos, SP, Brazil'. The correct affiliation is listed below.

'Department of Medicine, Federal University of São Carlos, SP, Brazil'

These errors have now been corrected in the PDF and HTML versions of the Article.

(i) Open Access This article is licensed under a Creative Commons Attribution 4.0 International License, which permits use, sharing, adaptation, distribution and reproduction in any medium or format, as long as you give appropriate credit to the original author(s) and the source, provide a link to the Creative Commons license, and indicate if changes were made. The images or other third party material in this article are included in the article's Creative Commons license, unless indicated otherwise in a credit line to the material. If material is not included in the article's Creative Commons license and your intended use is not permitted by statutory regulation or exceeds the permitted use, you will need to obtain permission directly from the copyright holder. To view a copy of this license, visit http://creativecommons.org/licenses/by/4.0/.

(C) The Author(s) 2020 